\title{
Bioactivities of Solanum xanthocarpum isolated from Western Ghats, Tamil Nadu, India
}

\author{
V. Manon Mani, S. Dhayalini, M. Shanmuga Priya and K. Preethi ${ }^{\star}$ \\ Department of Microbial Biotechnology, Bharathiar University, Coimbatore - 641046, Tn, India. \\ *Corresponding author. Email: gunpre77@gmail.com
}

Copyright (C) 2016 Mani et al. This article remains permanently open access under the terms of the Creative Commons Attribution License 4.0, which permits unrestricted use, distribution, and reproduction in any medium, provided the original work is properly cited.

Received 10th March, 2016; Accepted 25th May, 2016

\begin{abstract}
The current research is mainly focused on the bio-products from natural sources. The natural products provide various applications as antimicrobial, antioxidant, antiviral agents. Even the potential anticancer drugs have been extracted from natural products. Keeping this in mind, the current research has been implemented to extract the antioxidants from a medicinal tree. The medicinal plants are found to have bioactivities and in this research Solanum xanthocarpum was taken. The different phytochemicals have been present in the plant extract and the extract explored the presence of flavonoids and alkaloids. The root, stem and leaf samples were subjected to chromatographic techniques and the compounds were separated from those extracts. The root, stem and leaf extract from the plant was taken for antimicrobial and antioxidant assessment. The antimicrobial profile was found to be highest in all the three extracts. Similarly, the plant extracts exhibited the antioxidant properties in a highest range at least concentration. The inhibition concentration was evaluated for the plant extracts. Further, the potential compound will be elucidated for the probable structure and biopotentiality.
\end{abstract}

Keywords: Antimicrobial, antioxidant, TLC, phytochemicals.

\section{INTRODUCTION}

An antioxidant is a molecule capable of slowing or preventing the oxidation of other molecules. Oxidation is a chemical reaction that transfers electrons from a substance to an oxidizing agent. Oxidation reactions can produce free radicals, which start chain reactions that damage cells. Antioxidants terminate these chain reactions by removing free radicals intermediates, and often inhibit reducing agents such as thiols, ascorbic acid or polyphenols. The term antioxidant originally was used specifically to refer to a chemical that prevented the consumption of oxygen. The possible mechanisms of action of antioxidants were first explored when it was recognized that a substance with anti-oxidative activity is likely to be one that is readily oxidized. Antioxidants are absolutely critical for maintaining optimal cellular and systemic health and well-being (Kaliora et al., 2006). To protect the cells and organ systems of the body against reactive oxygen species, humans have evolved a highly sophisticated and complex antioxidant protection system. It involves a variety of components, both endogenous and exogenous in origin, that function interactively and synergistically to neutralize free radicals. Screening of antioxidants in plants is done by measuring the antioxidant activity through various in vitro models like DPPH method, nitric oxide method, DMPD method, ABTS method, ORAC method, TBARS assay and so on.

Solanum xanthocarpum, also known as the Thai eggplant, is a medicinal herb common in Bangladesh, Nepal and India. The Thai eggplant (S. xanthocarpum) is a variety of eggplant used in Southeast Asian cuisines. It is also cultivated in Sri Lanka and used in Sri Lankan cuisine. The most common eggplants in Thai cooking are the round white or green ones about the size of a golf ball. Common cultivar types in Thailand are Thai Purple, Thai Green, Thai Yellow, and Thai White. According to Smith and Wujastyk (2008), it is used for treating bronchitis, asthma, fever, lumbago, piles (specially bleeding piles), thirst, urinary and heart disease.

The fruits are glabrous, globular berries, green and white strips when young but yellow when mature. The fruits are known for several medicinal uses like anthelmintic, antipyretic, laxative, anti-inflammatory, 
antiasthmatic and aphrodisiac activities. The stem, flowers and fruits are prescribed for relief in burning sensation in the feet accompanied by vesicular eruptions. $S$. xanthocarpum exhibits larvicidal property, it kills Anopheles spp, Aedes spp. \& Culex spp. which are the important mosquito vectors prevalent in arid regions. The methanolic extract of $S$. xanthocarpum showed significant antinociceptive activity in mice. It exhibits antifungal property. It shows cidal effect on Aspergillus flavus, A.niger and A.fumigatus. Fruit extract of $S$. xanthocarpum was evaluated for its toxicity against Alternaria brassicae, the causal agent of Alternaria blight of Indian mustard. The anti-diabetic potentials of aqueous extract of $S$. xanthocarpum fruits was studied in normal and streptozotocin-induced hyperglycemic rats. Considering the medicinal value of $S$. xanthocarpum the investigation has been carried on to evaluate the antimicrobial and antioxidant potentiality through several assays and the presence of phytochemical constituents were determined.

\section{MATERIALS AND METHODS}

\section{Preparation of plant extract}

The root, stem and leaf of $S$. xanthocarpum were shade dried and powdered using a mixture. The powdered samples were subjected to the successive Soxhlet extraction. About $34.9 \mathrm{~g}$ of each sample were weighed and the crude compounds were extracted using $230 \mathrm{ml}$ of ethyl acetate and methanol successively for a period of 3 hours. The extract obtained were concentrated to dryness is a rotary vacuum evaporator under reduced pressure and controlled temperature and stored at $4^{\circ} \mathrm{C}$ in the refrigerator until further use.

\section{Partial purification method}

The crude extract was subjected to Thin Layer Chromotography (TLC) (Mani et al., 2015). About 5 microliter of the crude extract was applied $1 \mathrm{~cm}$ above from the lower edge of the thin layer chromatography slides and dried. It was immersed to a depth of $1 \mathrm{~cm}$ in the solvents. The different solvent system tested for movement of the pigment was chloroform: methanol and petroleum ether: ethyl acetate. The best solvent system for the separation of the components in the crude extract was taken. The solvent front was marked and $R_{f}$ value was calculated.

\section{Qualitative phytochemical analysis}

The phytochemicals such as alkaloids, flavnoids, steroids, tannins, phenols, cardiac glycosides, carbohydrates and saponins were determined following Mani et al. (2015).

\section{Biological activity}

$0.1 \mathrm{mg} / \mathrm{ml}$ of the crude plant extract was taken for biological studies.

\section{Anti-microbial activity}

The anti-microbial activity was carried out by well diffusion method (Bauer et al., 1966) against clinical pathogens (PSG Hospital, Coimbatore) Staphylococcus aureus, Staphylococcus epidermidis, Escherichia coli, Pseudomonas aeruginosa, Klebsiella pnuemoniae, Salmonella typhi, Proteus sp, Shigella sp, Candida albicans and Aspergillus niger. The Mueller Hinton agar plates were prepared and the test organisms were swapped. The wells were cut by using a sterile cork borer. Forty micro liter of each extract sample was poured in each well and incubated at $37^{\circ} \mathrm{C}$ for $24 \mathrm{hr}$ for bacteria and $28^{\circ} \mathrm{C}$ for $48 \mathrm{hr}$ for fungi.

\section{Anti-oxidant activities}

DPPH radical scavenging assay: The free radical scavenging activity of the fractions was measured in vitro by 2, 2- diphenyl-1-picrylhydrazyl (DPPH) assay according to the method earlier described by BrandWilliams et al. (1995) and Bursal et al. (2011). The stock solution was prepared by dissolving $24 \mathrm{mg}$ DPPH with $100 \mathrm{ml}$ methanol and stored at $20^{\circ} \mathrm{C}$ until required. The working solution was obtained by diluting DPPH solution with methanol to attain an absorbance at $517 \mathrm{~nm}$ using the spectrophotometer. A $3 \mathrm{ml}$ aliquot of this solution was mixed with $100 \mu \mathrm{l}$ of the sample at various concentrations (10 to $50 \mu \mathrm{g} / \mathrm{ml}$ ). The reaction mixture was well shaken and incubated in the dark for $15 \mathrm{~min}$ at room temperature. Then, the absorbance was taken at $517 \mathrm{~nm}$. The control was prepared as described above without any sample. The ability to scavenge DPPH radical was calculated by the following equation:

DPPH radical scavenging activity $(\%)=[($ Abs control - Abs sample)]/ (Abs control) $\times 100$

Metal chelating activity: The iron chelating activity was measured by the decrease in absorbance at $562 \mathrm{~nm}$ of the iron (II) - ferrozine complex (Mani et al., 2015b). The reaction mixture contained $0.5 \mathrm{ml}$ of ferric chloride $(0.6$ $\mathrm{mM}$ ) and $900 \mu \mathrm{l}$ methanol. The mixture was shaken and left at room temperature for $10 \mathrm{~min}$. To this, $0.1 \mathrm{ml}$ of ferrozine $(5 \mathrm{mM})$ in methanol was added, mixed and left for $5 \mathrm{~min}$ to form a complex residual $\mathrm{Fe}^{2+}$. The absorbance of the resulting solution was measured at $562 \mathrm{~nm}$. The ability of the sample to chelate ferrous ion was calculated relative to the control (consisting of iron and ferrozine only) using the formula: 
Table 1. Phytochemical screening for the plant extracts

\begin{tabular}{lccc}
\hline Phytochemicals & Stem Extract & Root Extract & Leaf Extract \\
\hline Alkaloids & - & - & - \\
Flavonoids & + & + & + \\
Phenols & + & + & + \\
Tannins & - & - & + \\
Cardiac Glycosides & + & - & + \\
Steroids & - & - & - \\
Saponins & - & - & + \\
\hline
\end{tabular}

(+) presence; (-) absence

Chelating effect $(\%)=\left[\left(\mathrm{A}_{\text {control }}-\mathrm{A}_{\text {sample }}\right) / \mathrm{A}_{\text {control }}\right] \times 100$.

Reducing power: Total reducing power was determined as described by Mani et al. (2015b). $1 \mathrm{ml}$ of sample solution at different concentrations was mixed with $2.5 \mathrm{ml}$ of phosphate buffer $(0.2 \mathrm{~mol} / \mathrm{l}, \mathrm{pH} 6.6)$ and $2.5 \mathrm{ml}$ of potassium ferricyanide $(1 \%)$. The mixture was incubated at $50^{\circ} \mathrm{C}$ for $20 \mathrm{~min}, 2.5 \mathrm{ml}$ of trichloroacetic acid (TCA, $10 \%$ ) was added to the mixture and centrifuged at $3000 \mathrm{~g}$ for $10 \mathrm{~min}$. The supernatant $(5 \mathrm{ml})$ was mixed with $1 \mathrm{ml}$ of ferric chloride $(0.1 \%)$, and the absorbance was measured at $700 \mathrm{~nm}$ in a Spectrophotometer. Increased absorbance of the reaction mixture indicated increased reducing power.

Hydroxyl radical scavenging activity: Hydroxyl radical scavenging activity was measured by the ability of the different fractions of $S$. xanthcarpum extract to scavenge the hydroxyl radicals generated by the Fe3+-ascorbateEDTA $-\mathrm{H}_{2} \mathrm{O}_{2}$ system (Fenton reaction) (llavarasan et al., 2005). The reaction mixture contained; $500 \mu \mathrm{l}$ of 2 deoxyribose $(2.8 \mathrm{mM})$ in phosphate buffer $(50 \mathrm{mM}, \mathrm{pH}$ 7.4), $200 \mu \mathrm{l}$ of premixed ferric chloride $(100 \mathrm{mM})$ and EDTA (100 mM) solution (1:1; v/v), $100 \mu \mathrm{l}$ of $\mathrm{H}_{2} \mathrm{O}_{2}(200$ $\mathrm{mM})$ with or without the extract solution $(100 \mu \mathrm{l})$. The reaction was triggered by adding $100 \mu \mathrm{l}$ of $300 \mathrm{mM}$ ascorbate and incubated for $1 \mathrm{hr}$ at $37^{\circ} \mathrm{C}$. $0.5 \mathrm{ml}$ of the reaction mixture was added to $1 \mathrm{ml}$ of TCA $(2.8 \%$; w/v; aqueous solution), then $1 \mathrm{ml}$ of $1 \%$ aqueous TBA were added to the reaction mixture. The mixture was heated for $15 \mathrm{~min}$ on a boiling water bath and allowed to cool. The absorbance at $532 \mathrm{~nm}$ was noted against a blank (the same solution but without reagent). The scavenging activity on hydroxyl radical was calculated as follows:

Scavenging activity $=$ (absorbance control - absorbance of sample / absorbance of control) $\times 100$

Total antioxidant capacity: The total antioxidant capacity of the fractions was determined by phosphomolybdate method using ascorbic acid as a standard (Umamaheswari et al., 2008). An aliquot of 0.1 $\mathrm{ml}$ sample solution was mixed with $1 \mathrm{ml}$ of reagent solution (0.6 M sulphuric acid, $28 \mathrm{mM}$ sodium phosphate and $4 \mathrm{mM}$ ammonium molybdate). The tubes were capped and incubated in a water bath at $95^{\circ} \mathrm{C}$ for $90 \mathrm{~min}$. The sample was allowed to cool at room temperature and the absorbance of the mixture was measured at $765 \mathrm{~nm}$ against a blank. A typical blank contained $1 \mathrm{ml}$ of the reagent solution and the appropriate volume of the solvent and incubated under the same conditions. Ascorbic acid was used as standard.

\section{RESULTS AND DISCUSSION}

\section{Preparation of plant extracts}

The root, stem and leaf of Solanum xanthocarpum were shade dried and powdered. The crude bioactive compounds were extracted using methanol. The crude extracts were taken for further studies.

\section{Phytochemical Analysis}

Preliminary phytochemical screening of the crude methanolic extract of the plant sample was carried out and the results were given in Table 1.

\section{TLC}

The best solvent system for movement of the pigment was found to be Acetone: petroleum ether. For stem extract the band was seen in 30\% (Acetone: Petroleum ether), for root sample the band was seen in $40 \%$ (Acetone: Petroleum ether) and for leaf sample the band was viewed in 20\% (Acetone: Petroleum ether) concentration. The solvent front was marked and $R_{f}$ value was calculated. Four bands were obtained through TLC (Figure 1 and Table 2).

\section{Biological activity}

\section{Antibacterial activity}

The antibacterial activity was carried out and the results 


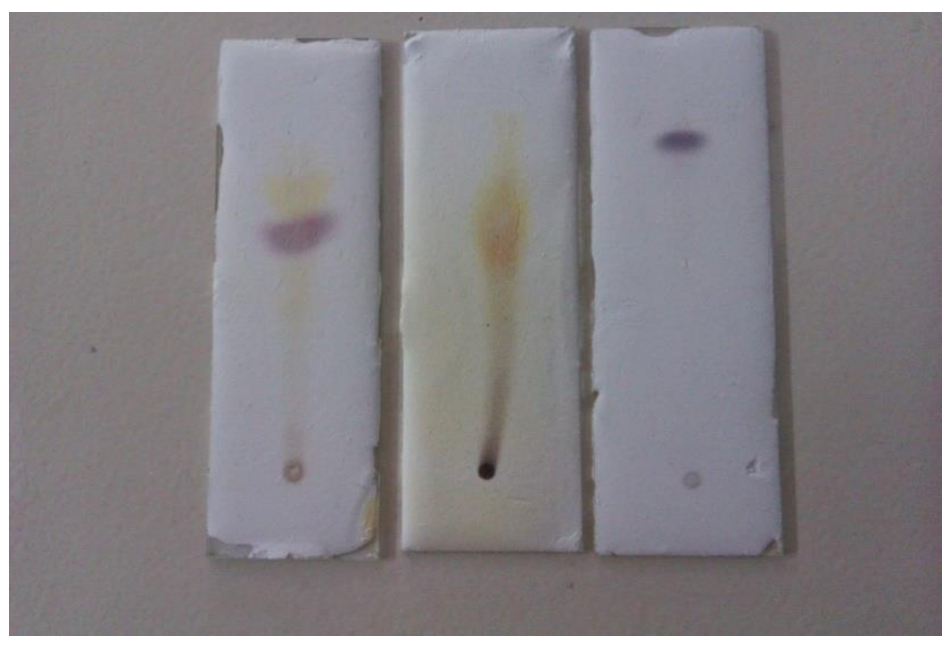

Figure 1. TLC of Plant extract.

Table 2. TLC for extracts of $S$. xanthocarpum (stem, root and leaf).

\begin{tabular}{|c|c|c|c|c|c|c|c|c|c|c|c|c|}
\hline \multirow{3}{*}{$\begin{array}{l}\text { Solvent concentration } \\
\text { (Acetone : Petroleum } \\
\text { ether) }\end{array}$} & \multicolumn{12}{|c|}{$\mathbf{R}_{\mathrm{f}}$ value } \\
\hline & \multicolumn{4}{|c|}{ Stem extract } & \multicolumn{4}{|c|}{ Leaf extract } & \multicolumn{4}{|c|}{ Root extract } \\
\hline & $\mathrm{I}$ & II & III & IV & $I$ & II & III & IV & $I$ & II & III & IV \\
\hline $10 \%$ & - & 1.6 & - & - & - & - & 2.5 & - & - & - & 1.7 & - \\
\hline $20 \%$ & - & - & 1.4 & - & 1.7 & - & - & 2.1 & - & 2.2 & - & - \\
\hline $30 \%$ & 5.5 & - & - & 2.7 & - & 4.5 & - & - & 3.3 & - & - & - \\
\hline $40 \%$ & - & - & 3.8 & - & 1.9 & - & 2.2 & - & - & 4.5 & - & 2.6 \\
\hline $50 \%$ & 1.2 & - & - & 1.8 & - & - & - & 1.4 & - & - & 1.3 & - \\
\hline
\end{tabular}

Table 3. Antibacterial activity of plant extracts.

\begin{tabular}{llc}
\hline Extract & Pathogens & Zone of Inhibition (diameter in cm) \\
\hline \multirow{4}{*}{ Stem } & Pseudomonas aeruginosa & 1.5 \\
& Proteus $s p$. & 0.7 \\
& Shigella sp. & 1.2 \\
& & \\
\multirow{2}{*}{ Root } & Pseudomonas aeruginosa & 1.5 \\
& Proteus $s p$. & 0.6 \\
& Shigella sp. & 0.5 \\
& & \\
\multirow{2}{*}{ Leaf } & Pseudomonas aeruginosa & 2.0 \\
& Proteus sp. & 0.6 \\
& Shigella sp. & 0.3 \\
& Klebsiella sp. & 1.5 \\
\hline
\end{tabular}

$(<0.5-$ No activity)

were observed. The stem, root and leaf extract inhibited Pseudomonas at 1.5, 1.5 and $2 \mathrm{~cm}$ respectively. The Shigella sp was highly susceptible to stem, root and leaf extract and formed inhibition of 1.2, 0.5 and $1.5 \mathrm{~cm}$ respectively (Table 3 and Figure 2).

\section{Antifungal Activity}

Antifungal activity was performed against the fungal strains Candida albicans and Aspergillus niger. The Candida albicans was highly susceptible to leaf extract of 

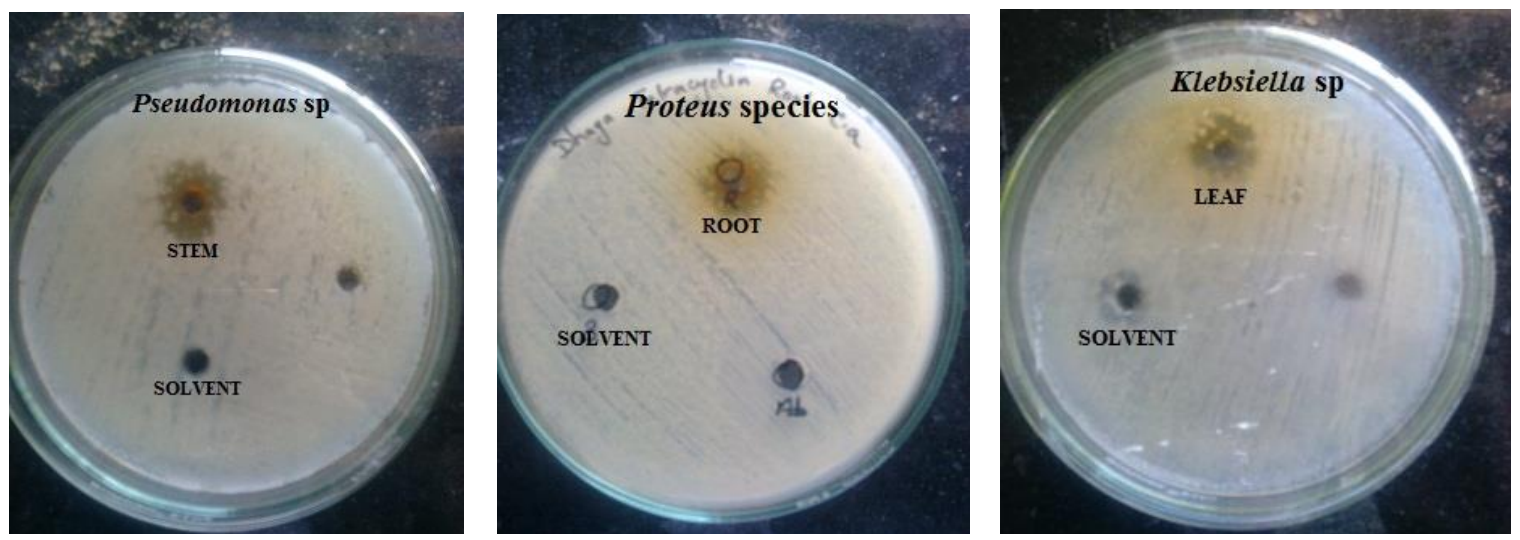

Figure 2. Antibacterial activity of plant extract Solanum xanthocarpum.
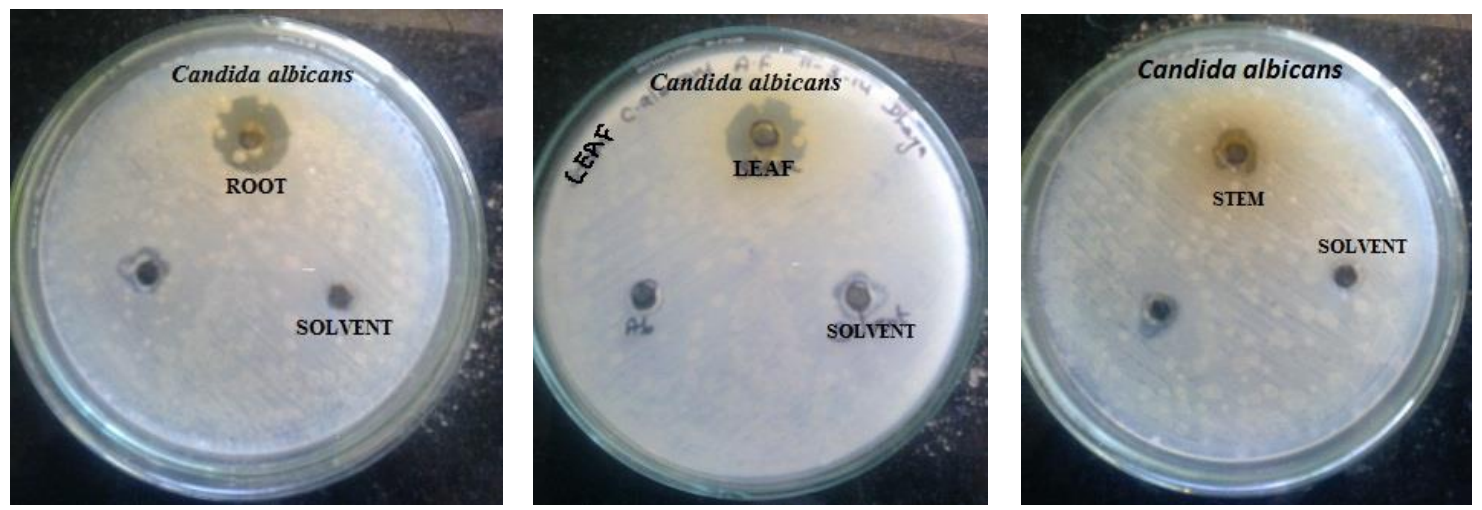

Figure 3. Antifungal activity of plant extracts Solanum xanthocarpum.

Table 4. Antifungal activity of plant extracts.

\begin{tabular}{llc}
\hline Extract & Fungal Strain & Zone of Inhibition (in cm) \\
\hline Stem & & 0.3 \\
Root & Candida albicans & 0.5 \\
Leaf & & 0.7 \\
\hline
\end{tabular}

Solanum xanthocarpum and inhibition zone of about 0.7 $\mathrm{cm}$ was obtained (Table 4 and Figure 3).

\section{Antioxidant Activity}

\section{$D P P H$ radical scavenging assay}

DPPH assay is one of the most widely used method for screening antioxidant activity of natural product. DPPH is stable, nitrogen centered free radical which produces violet colour in methanol solution (Mani et al., 2015). When the sample was added in a dose dependent manner the DPPH was reduced to a yellow coloured product, diphenylpicryl hydrazine. The reduction in the number of DPPH molecules can be correlated with the number of available hydroxyl groups. Scavenging of DPPH represents the free radical reducing activity of antioxidants based on a one electron reduction. Scavenging DPPH free radical determines the free radical scavenging capacity or antioxidant potential (AOD) of the sample, which shows its effectiveness prevention, interception and repair mechanisms against injury in a biological system (Lee et al., 2001).

Significant DPPH scavenging potential of methanol extract of two microorganisms may be due to hydroxyl groups present in the extracts (Nithya et al., 2011). The $\mathrm{IC}_{50}$ value of the plant extracts of stem, root and leaf was $2.6 \mu \mathrm{g} / \mathrm{ml}, 3.1 \mu \mathrm{g} / \mathrm{ml}$ and $1.1 \mu \mathrm{g} / \mathrm{ml}$ respectively (Figure 4). At $50 \mu l$ concentration, the samples which contain $0.005 \mathrm{mg} / \mathrm{ml}$ of root, stem and leaf showed inhibition activity of $5.9 \mu \mathrm{g} / \mathrm{ml} \%, 7.2 \mu \mathrm{g} / \mathrm{ml} \%$ and $6.8 \mu \mathrm{g} / \mathrm{ml} \%$ respectively which was greater than the standard ascorbic acid.

\section{Reductive ability}

For the measurement of the reducing ability, the $\mathrm{Fe}^{3+} \mathrm{Fe}^{2+}$ 


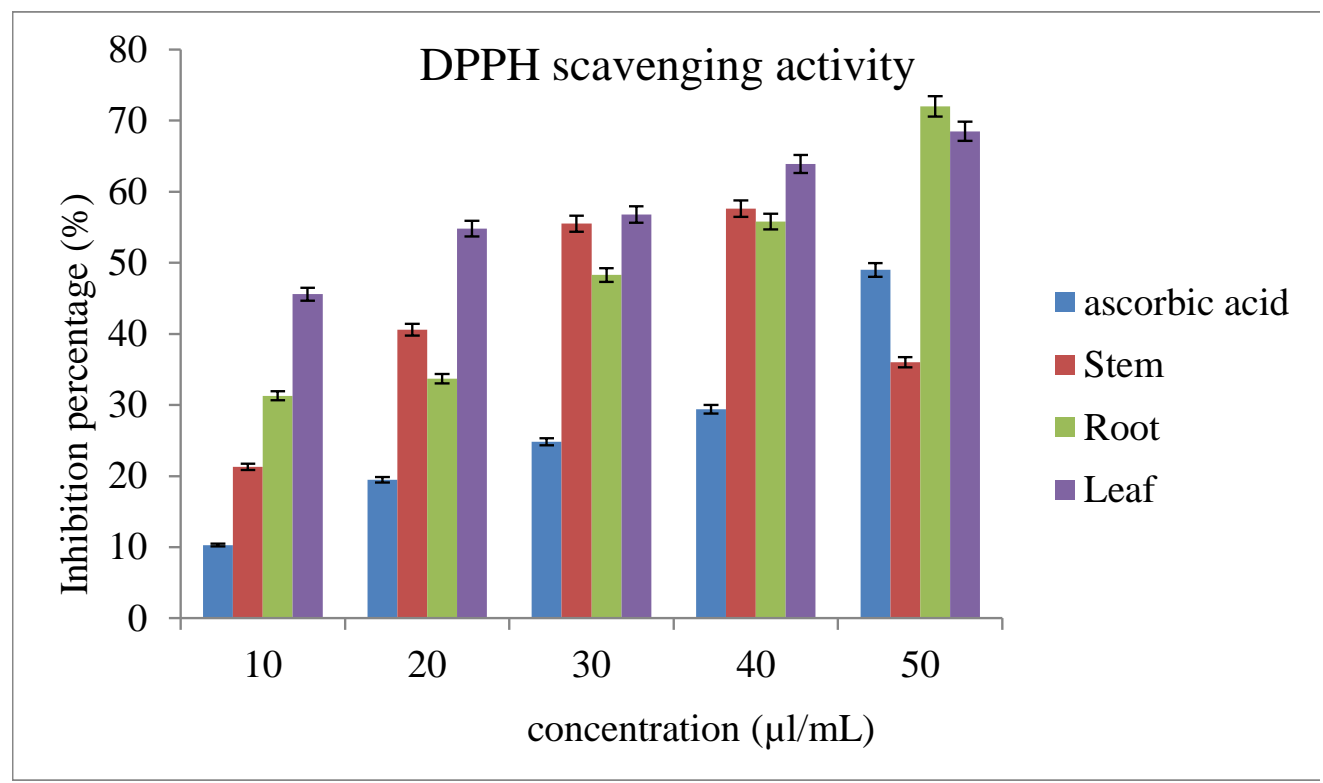

Figure 4. DPPH scavenging activity for plant extracts.

Table 5. Reductive ability activity for Stem, Root and Leaf Extracts.

\begin{tabular}{lcc}
\hline Extract & Concentrations $(\mu \mathrm{l} / \mathrm{mL})$ & OD Value \\
\hline Stem & 10 & 0.018 \\
& 20 & 0.19 \\
& 30 & 0.22 \\
& 40 & 0.36 \\
& 50 & 0.42 \\
Root & 10 & 0.19 \\
& 20 & 0.27 \\
& 30 & 0.31 \\
& 40 & 0.39 \\
Leaf & 50 & 0.47 \\
& 10 & 0.2 \\
& 20 & 0.24 \\
& 30 & 0.28 \\
& 40 & 0.33 \\
& 50 & 0.4 \\
\hline
\end{tabular}

transformation was investigated in the presence of methanolic crude extract. The reducing capacity of the compound may serve as a significant indicator of their potential antioxidant activity. However, the antioxidants has been assigned to various mechanisms such prevention of chain initiation, binding of transition- metal ion catalysts, decomposition of peroxides and prevention of continued hydrogen abstraction, reductive capacity and radical scavenging.

Similar to the antioxidant activity, the reducing power of methonolic extract of the plant extract of $S$. xanthocarpum (stem, root and leaf) increased with increasing dosage. The result showed that methanolic crude extract of hydrophilic poly phenolic compounds that causes the greater reducing power. As the OD value increases the reducing capacity also increases as shown in Table 5.

\section{Metal chelating activity}

In the assay plant extracts, interfered with the formation 


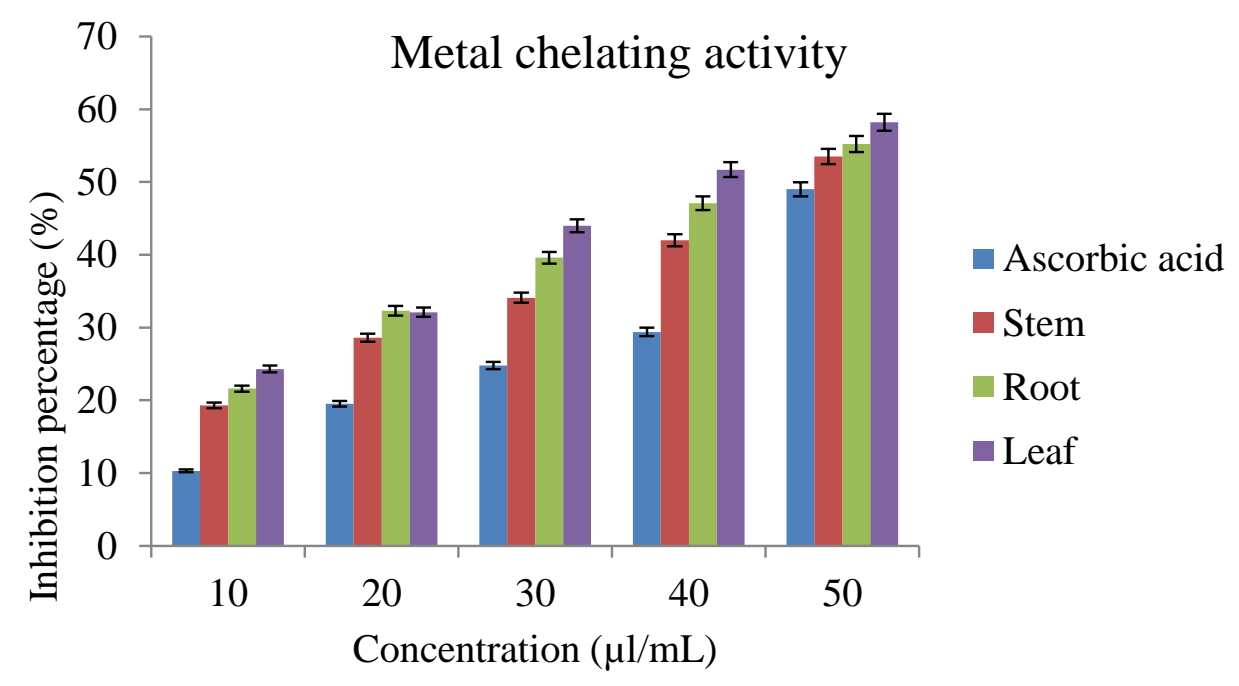

Figure 5. Metal chelating activity for plant extracts.

of ferrous and ferrozine complex, indicating the presence of chelating activity which captured ferrous ion before ferrozine and it can quantitatively form complexes with $\mathrm{Fe}^{+}$in the presence of other chelating agents (Mani et al., $2015 b)$. The complex formation is disrupted which is determined by the decrease in red colour. Measurement of the rate of colour reduction was used to estimate the chelating activity of the coexisting chelator. It was reported that chelating agents that form $r$ - bonds with a metal are effective as secondary antioxidants because they reduce the redox potential thereby stabilizing the oxidized form of the metal iron. So the plant extracts were able to have the chelation activity at the concentration of $3.5 \mu \mathrm{g} / \mathrm{ml}, 4.4 \mu \mathrm{g} / \mathrm{ml}$ and $2.0 \mu \mathrm{g} / \mathrm{ml}$ for root, stem and leaf extracts respectively (Figure 5 ).

\section{Hydroxyl radical scavenging activity}

Hydroxyl radical scavenging assay showed the abilities of the extract and standard mannitol in inhibiting hydroxyl radical mediated deoxyribose degradation in a $\mathrm{Fe}^{3+}$ EDTA ascorbic acid and $\mathrm{H}_{2} \mathrm{O}_{2}$ reaction mixture. Hydroxyl radicals are the major active oxygen species using enormous biological damage by lipid peroxidation in cells. When a hydroxyl radical reacts with aromatic compounds, hydroxycyclohexadienyl radical is formed, which will undergo further reaction with oxygen, to give perooxyl radical, or decompose to phenoxyl-type radicals by water elimination. Hydroxyl radical were produced in this study by incubating ferric EDTA with ascorbic acid and $\mathrm{H}_{2} \mathrm{O}_{2}$ at $\mathrm{pH} 7.4$ and reacted with 2-Deoxy -2-ribose to generate a malondialdehyde (MDA) like product. This compound forms a pink chromogen upon heating with TBA. The samples were added to the reaction mixture to remove the hydroxyl radicals from the sugar and prevent the reaction. The plant samples showed the activity by eliminating hydroxyl radicals in a dose dependent manner. Different concentration in different plant samples exhibited the activity (root sample: $4.2 \mu \mathrm{g} / \mathrm{ml}$, stem sample: $4.8 \mu \mathrm{g} / \mathrm{ml}$, leaf sample: $3.6 \mu \mathrm{g} / \mathrm{ml}$ ) (Figure 6).

\section{Total antioxidant activity}

The lifespan of a plant is tightly connected with its stability to the environmental factors, which is determined by the state of the cell antioxidant defence components e.g phenolic compounds. Phenolic and flavonoid compounds seem to have important role in stabilizing lipid oxidation and to be associated with antioxidant activity, which is emphasized in several reports (Mani et al., 2015b). The mechanism of action of flavonoids is through scavenging or chelation and phenolic compounds are also very important plant constituents because their hydroxyl groups confer scavenging ability. The plant extracts contained the total antioxidant activities of about $3.0 \mu \mathrm{g} / \mathrm{ml}$ (root), $2.3 \mu \mathrm{g} / \mathrm{ml}$ (stem) and $2.1 \mu \mathrm{g} / \mathrm{ml}$ (leaf) which were equivalent to standard ascorbic acid.

\section{Conclusion}

Different parts of the plant $S$. xanthocarpum such as root, stem and leaf were taken to extract the bioactive products using methanol. Qualitative phytochemical screening was carried out for these three extracts and all the three extracts showed the presence of alkaloids and phenols. The leaf extract showed the presence of tannins, glycosides and saponins. The thin layer chromatography was done to separate the compounds. It 


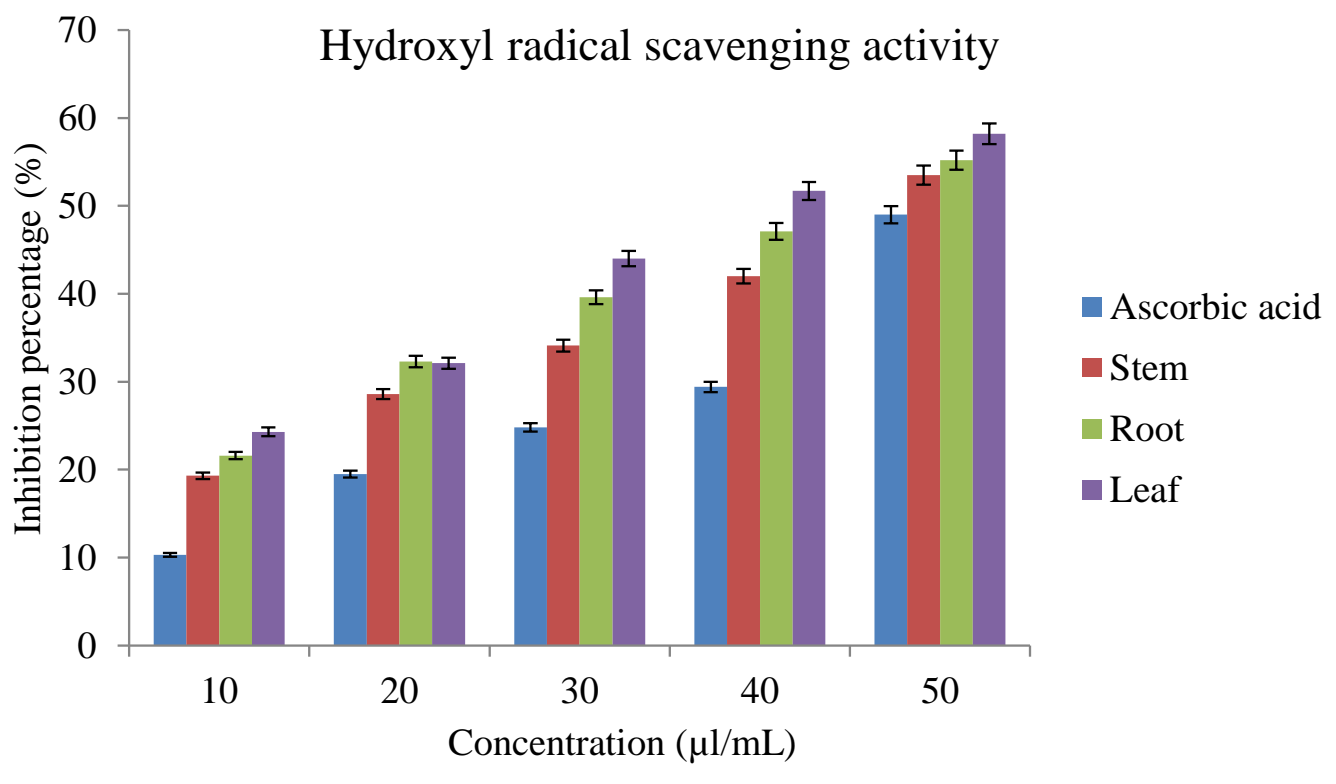

Figure 6. Hydroxyl radical scavenging activity for plant extracts.

means that the extracts may contain flavonoids and phenols which were concluded from the calculation of $R_{f}$ value. This plant extracts were subjected to antimicrobial and antioxidant activities. The extracts were found to inhibit Pseudomonas aeruginosa, Shigella $\mathrm{sp}$ and Proteus sp. The root, stem and leaf extracts were taken to determine the antioxidant activities such DPPH assay, reducing power, hydroxyl radical scavenging activity, iron chelating activity and total antioxidant capacity. The activity was found in 1 to $5 \mu \mathrm{g} / \mathrm{ml}$ for root, stem and leaf extracts of $S$. xanthocarpum. From this study, it is evident that the plant extract has the antimicrobial and antioxidant potential.

\section{CONFLICT OF INTEREST}

The authors declare that they have no conflict of interest.

\section{REFERENCES}

Bauer, A.W., Kirby, W. M. M. M., Sherris, J.C., \& Turch, M., (1966). Antibiotic susceptibility testing by a standardized single dics method. American Journal of clinical. Pathology. 45(4), 493-496.

Bursal, E., \& Gulcin., (2011). Polyphenol contents and in vitro antioxidant activities of lyophilized aqueous extract of kiwi fruit (Actinidia deliciosa). Food Research Institute. 44, 14821489. llavarasan, R., Maliga, M., \& Venkataraman, S., (2005). Antiinflammation and antioxidant activities of Cassla fistula Linn, bark extracts. African Journal Traditional, complementary and alternative medicines. 2, 70-85.

Kaliora, A.C., Dedoussis, G.V., \& Schmidt, H., (2006). Dietary antioxidants in preventing atherogenesis. Journal of Atherosclerosis. 187, 1-17.

Lee, S. E., Ju, E. M., \& Kim, J.H., (2001). Free radical scavenging and antioxidant enzyme fortifying activities of extracts from Smilax china root. Experimental Molecular Medicine. 33, 263-268.

Manon Mani, V., Parimala Gnana Soundari, A., Karthiyaini, D., \& Preethi, K., (2015b). Bioprospecting for endophytic fungi and their metabolites from medicinal tree Aegle marmelos in Western Ghats, India. Mycobiology, 43(3), $303-310$. doi: 10.5941/MYCO.2015.43.3.303.

Manon Mani, V., Shanmuga Priya, M., Dhaylini, S., \& Preethi, K., (2015a). Antioxidant and antimicrobial evaluation of bioactive pigment from Fusarium sp isolated from stressed environment. International Journal of Current Microbiology and Applied Sciences. 4(6), 1147-1158.

Smith, F. M., \& Wujastyk, D. (Eds.). (2008). Modern and Global Ayurveda: Pluralism and Paradigms. State University of New York Press.

Umamaheswari, M., \& Chatterjee, T.K., (2008). In vitro antioxidant activities of the fractions of coccinnia grands $L$. Leaf extract. African Journal Traditional, complementary and alternative medicines. 5, 61-73.

Williams W.B., Cuvelier, M. E., \& Berset, C., (1995). Use of free radical method to evaluate antioxidant activity. Lebens mitter Wissenschaft under Technology, 28, 25-30. 